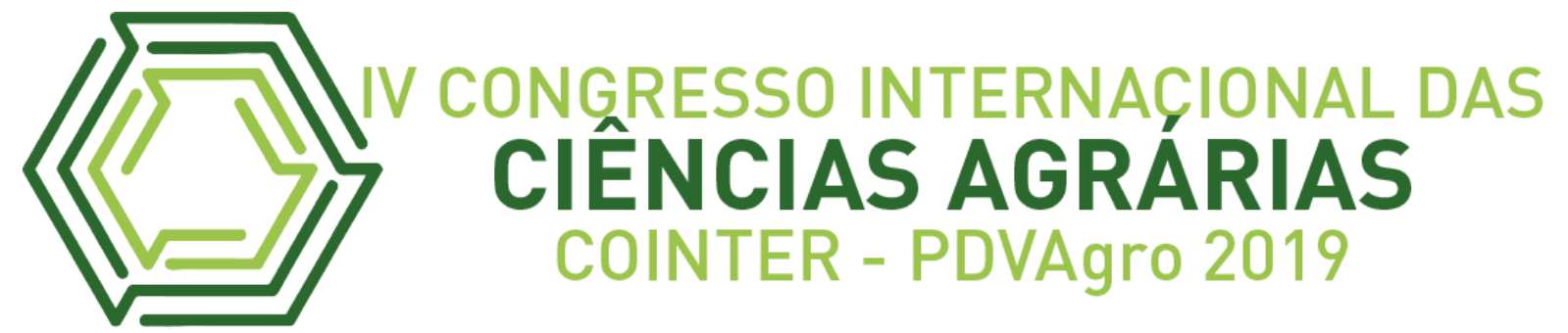

\title{
DIFICULDADES E ESTRATÉGIAS NA COMERCIALIZAÇÃO DE PRODUTOS DA FEIRA LIVRE DA QUATORZE DE MARÇO EM CAPANEMA, PARÁ.
}

\author{
DIFICULTADES Y ESTRATEGIAS EN MARKETING MARZO CATORCE \\ PRODUCTOS DE MERCADO LIBRE EN CAPANEMA, PARÁ.
}

\section{DIFFICULTIES AND STRATEGIES IN MARKETING MARCH FOURTEEN FREE MARKET PRODUCTS IN CAPANEMA, PARÁ.}

\author{
Apresentação: Comunicação Oral \\ Raylan Costa de Oliveira ${ }^{1}$; Elaine de Oliveira Neto ${ }^{2}$; Ana Karla Magalhães Nogueira ${ }^{3}$
}

DOI: $\underline{\text { https://doi.org/10.31692/2526-7701.IVCOINTERPDVAgro.2019.0087 }}$

\begin{abstract}
Resumo
$\mathrm{O}$ presente trabalho objetivou mostrar as principais dificuldades e estratégias de comercialização nos produtos dos feirantes da feira livre da Quatorze de Março na cidade de Capanema, Nordeste Paraense. A pesquisa foi realizada no período compreendido entre os dias 9 e 10 de fevereiro, baseando-se na coleta de dados por meio da aplicação de um questionário semiestruturado contendo 35 perguntas fechadas. A partir disso, foram analisados fatores, como: presença ou ausência de organizações de comerciantes, participação dos comerciantes em grupos ou organizações, tipo de cultivo (orgânico e convencional) e marketing, relacionando-os com estratégias na comercialização dos produtos, além das principais dificuldades enfrentadas por essas pessoas, no processo de comercialização. Os dados coletados foram sistematizados através de uma análise percentual relacionada a cada item apresentado, com auxílio do programa Excel versão 2010. Os resultados mostraram que $55 \%$ dos entrevistados produzem, total ou parcial, os produtos comercializados em seus estabelecimentos. Há ausência de organizações, grupos ou movimentos entre os feirantes, mesmo 50\% deles apresentando interesse em participar. Os consumidores da feira da Quatorze demandam em sua maior parte $(82 \%)$ produtos cultivados de forma convencional, por esse motivo apenas $36 \%$ dos produtos comercializados são produzidos de forma orgânica, tendo como maior peso na aquisição de um produto o preço, sendo este a principal dificuldade na comercialização (27\%). Em relação à infraestrutura o fator "espaço insuficiente" se comportou de forma mais expressiva. Como forma de divulgação dos seus produtos os feirantes utilizam o método denominado "boca a boca", correspondendo a $56 \%$ dos resultados, sendo esta uma das principais estratégias de comercialização. É bem visível a falta de interesse do poder público quanto às dificuldades enfrentadas pelos feirantes, uma vez que
\end{abstract}

\footnotetext{
${ }^{1}$ Agronomia, Universidade Federal Rural da Amazônia, Raylancostoli197@gmail.com

${ }^{2}$ Agronomia, Universidade Federal Rural da Amazônia, elaynne.cierre@gmail.com

${ }^{3}$ Doutora em desenvolvimento sustentável do trópico úmido, Universidade Federal do Pará, Karlla_ufra@gmail.com
} 
estes estão desenvolvendo suas atividades de forma independente e elaborando suas próprias estratégias de comercialização, fundamentadas em conhecimentos empíricos e com isso tentando contornar seus problemas.

Palavras-Chave: Feirantes. Fatores limitantes. Comercio.

\title{
Resumen
}

El presente trabajo tuvo como objetivo mostrar las principales dificultades y estrategias de marketing en los productos de los vendedores justos de Quatorze de Março en Capanema, Noreste Paraense. La investigación se realizó del 9 al 10 de febrero, basada en la recopilación de datos mediante la aplicación de un cuestionario semi-estructurado que contiene 35 preguntas cerradas. A partir de esto, analizamos factores como: presencia o ausencia de organizaciones de comerciantes, participación de comerciantes en grupos u organizaciones, tipo de cultivo (orgánico y convencional) y comercialización, relacionándolos con estrategias en la comercialización de productos, además de los principales. Dificultades que enfrentan estas personas en el proceso de comercialización. Los datos recopilados se sistematizaron mediante un análisis porcentual relacionado con cada ítem presentado, con la ayuda del programa Excel versión 2010. Los resultados mostraron que el 55\% de los entrevistados producen, total o parcialmente, los productos vendidos en sus establecimientos. Hay una ausencia de organizaciones, grupos o movimientos entre los vendedores, incluso el $50 \%$ de ellos muestran interés en participar. Los consumidores de Quatorze exigen, en su mayoría (82\%) productos cultivados de manera convencional, por esta razón solo el $36 \%$ de los productos vendidos se producen orgánicamente, siendo el precio el mayor peso en la compra de un producto. La principal dificultad en marketing (27\%). En cuanto a la infraestructura, el factor "espacio insuficiente" se comportó de manera más expresiva. Como medio para publicitar sus productos, los especialistas en marketing utilizan el método llamado "boca a boca", que representa el 56\% de los resultados, que es una de las principales estrategias de marketing. La falta de interés público en las dificultades que enfrentan los comerciantes justos es claramente visible, ya que están desarrollando sus actividades de forma independiente y desarrollando sus propias estrategias de marketing, basadas en el conocimiento empírico y tratando de solucionar sus problemas.

Palabras Clave: Comercializadores. Factores limitantes. Comercio

\begin{abstract}
The present work aimed to show the main difficulties and marketing strategies in the products of the fair marketers of Quatorze de Março in Capanema, Northeast Paraense. The research was conducted from February 9 to 10, based on data collection through the application of a semi-structured questionnaire containing 35 closed questions. From this, we analyzed factors such as: presence or absence of traders' organizations, participation of traders in groups or organizations, type of cultivation (organic and conventional) and marketing, relating them to strategies in the marketing of products, besides the main ones. Difficulties faced by these people in the marketing process. The collected data were systematized through a percentage analysis related to each item presented, with the aid of the Excel version 2010 program. The results showed that $55 \%$ of the interviewees produce, totally or partially, the products sold in their establishments. There is an absence of organizations, groups or movements among
\end{abstract}


marketers, even $50 \%$ of them showing interest in participating. Quatorze consumers demand, in their majority $(82 \%)$ conventionally grown products, for this reason only $36 \%$ of the products sold are produced organically, with the largest weight in the purchase of a product being price. the main difficulty in marketing (27\%). Regarding infrastructure, the "insufficient space" factor behaved more expressively. As a means of publicizing their products, marketers use the method called "word of mouth", accounting for $56 \%$ of the results, which is one of the main marketing strategies. The lack of public interest in the difficulties faced by the fair traders is clearly visible, as they are developing their activities independently and developing their own marketing strategies, based on empirical knowledge and trying to get around their problems.

Keywords: Marketers. Limiting factors. Trade.

\section{Introdução}

Segundo Vieira (2004), as feiras livres são práticas comerciais muito antigas, é o que gera a comercialização e fornecimento de alimentos para a mesa de uma considerável parte da população brasileira. Apesar de ser um modelo comercial defasado, realiza o desenvolvimento econômico e social, promovendo a economia das pequenas cidades dos interiores. Do ponto de vista do feirante e do consumidor as feiras livres desempenham um papel muito importante, que vai além do socioeconômico, pois a mesma tem representatividade no espaço público e cultural, tornando um ambiente dinâmico e diversificado. Godoy e Dos Anjos (2007) afirmam que esse sistema de comercialização vai além da compra e venda de produtos, envolve também a importância ao sistema de produção e seus produtores.

As feiras livres apresentam forte relação com a agricultura familiar, uma vez que essa é a principal responsável por abastecer os estabelecimentos que compõem esses espaços, o que por consequência assume um importante papel social, como a geração de renda, em duas situações distintas: Indiretamente pela necessidade de mão-de-obra no processo de produção e diretamente no processo abastecimento e comercialização desses produtos nas feiras (MICHELLON, 2007).

Segundo Costa et al. (2012) as feiras livres se constituem como um importante canal de distribuição de produtos advindos da agricultura familiar, uma vez que permite a comercialização direta entre os produtores e os consumidores. Isso por sua vez, torna possível um fornecimento de produtos sem exigir regularidade de oferta e padronização de produtos, como acontece em outras instituições comerciais (varejo tradicional). Essa distribuição valoriza relação consumidor-feirante, caracterizada por se basear na afetividade. 
Segundo Godoy (2011), o consumidor procura tomar posse se pertencer a um lugar através das comunidades onde reportam suas condições de vida de lado a lado com as relações sociais tomando como base a reciprocidade e cooperação. Dar-se em destaque o mercado consumidor, nichos, convite social, consumo e ferramentas clássicas da economia, a adequação de conceitos do marketing comercial clássico se volta para o campo social (FONTES, 2008).

A intensificação do processo de urbanização tem favorecido cada vez mais mercados varejistas formais (ex.: supermercados e shopping) e paralelamente a esse tipo de mercado encontra-se o mercado varejista informal (feira). Como forma de manter-se na concorrência as feiras apostam em estratégias de comercialização que buscam atrair um público-consumidor característico (ASSUMPÇÃO et al., 2013; COELHO; PINHEIRO, 2009).

Como mostrado por Tello et al. (2015), um dos principais produtos comercializados em feiras, as hortaliças, são produzidas em outras localidades e transportadas até esses espaços comerciais. Essa dinâmica, por sua vez, torna-se um dos principais entraves no processo comercial desses produtos. Dessa forma, os mesmos autores recomendam a realização de estudos que visam caracterizar a comercialização e os comerciantes desses espaços, afim de que se possa com isso melhorar a eficiência dessa relação comercial.

A feira da Quatorze de Março e por sua vez uma das mais tradicionais e importantes feiras do município de Capanema, entre os produtos comercializados podemos encontrar com maior expressividade os alimentícios, como: hortaliças em geral, frutas e carnes de origem bovinas, suínas e de aves. O seu funcionamento acontece todos os dias da semana nos três turnos e visa atender o consumidor que demanda produtos de menores preços.

Nesse contexto, este trabalho tem por objetivo identificar as dificuldades e estratégias de comercialização nos produtos dos feirantes da feira livre da Quatorze de Março no município de Capanema, Nordeste Paraense.

\section{Fundamentação Teórica}

Os feirantes têm estabelecidos estratégias de marketing de modo informal para obter vantagens na competitividade entre seus concorrentes. Tais métodos não possui um padrão estabelecido, devido à falta de conhecimento e assistência técnica por profissionais específicos. Para atingir o público alvo os feirantes utilizam os pilares dos "4 Ps" do 
marketing, que são: Produto, preço, praça e promoção. Os quatro Ps são fatores determinantes na gestão e na compra dos produtos agregando valor ao mesmo (SOUZA et al., 2015).

A principal dificuldade enfrentada pelos feirantes está na falta de infraestrutura, esses buscam de alguma forma melhorias em seus estabelecimentos. O que demonstra insatisfação dos feirantes ao Poder público, pois cabe a esses fazer a manutenção das mesmas e proporcionar local apropriado para os feirantes (CORÁ; BEGNINI; RECH, 2011).

Dificuldades no transporte dos produtos para a feira, fraco movimento no final do mês e ocorrência de pragas no processo de produção são para os vendedores que produzem seus produtos comercializados um dos fatores que mais limitam essa atividade (DIAS; SANTOS; ALMEIDA, 2018). Ao mesmo tempo os autores mostram que a comercialização dos produtos em feira tem se tornado uma estratégia, uma vez que esse espaço possibilitou um aumento nas vendas, entre os entrevistados.

Um fator que atua muito na aquisição de um produto no momento da compra é o preço. Nas feiras a formação do preço de um produto leva em consideração não só os custos de produção, o cliente e a concorrência são componentes que influenciam fortemente no estabelecimento dos preços (SILVEIRA et al., 2017).

\section{Metodologia}

A pesquisa em questão foi realizada no município de Capanema, situado na microrregião dos caetés, nordeste do estado do Pará. Contou com a participação de 11 feirantes oriundos da agricultura familiar, atuantes em uma das principais feiras do município (Feira da Quatorze).

A pesquisa baseou-se na coleta de dados por meio da aplicação de um questionário semiestruturados contendo 35 perguntas fechadas. Sendo aplicadas nos dias compreendidos entre 9 e 10 de fevereiro de 2019. As perguntas foram elaboradas de forma a englobar os principais desafios e estratégias presentes no fluxo comercial dos produtos comercializados na feira da quatorze.

A partir disso, foram analisados os seguintes fatores: presença ou ausência de organizações de comerciantes (cooperativa, associações, grupos informais e outros), participação dos comerciantes em grupos ou organizações, tipo de cultivo (orgânico e convencional) e marketing, relacionando-os com estratégias na comercialização dos produtos, além das principais dificuldades enfrentadas por essas pessoas, no processo de 
comercialização dos seus produtos como: infraestrutura, transporte, auxílio do poder público, preços e etc. Os dados coletados foram sistematizados através de uma análise percentual relacionada a cada item apresentado, com auxílio do programa Excel versão 2010.

\section{Resultados e Discussão}

A feira da Quatorze é uma das principais fontes de aquisição de produtos advindo da horticultura e fruticultura por parte dos consumidores menos favorecidos economicamente, no município de Capanema-PA. Esses produtos são, em sua maioria, produzidos no próprio município ou nas regiões pertencentes a este, onde 55\% dos entrevistados alegaram produzir, total ou parcial, os produtos comercializados em seus estabelecimentos. Aos feirantes que adquirem os produtos de terceiros foi questionado sobre a origem de tais mercadorias e $47 \%$ deles responderam conseguir de produtores da própria cidade, ou de municípios pertencente a ela, os demais dados se comportaram da seguinte forma: $29 \%$ adquirem as mercadorias de produtores de outras cidades, $24 \%$ da Ceasa e $0 \%$ outros.

Figura 1: Origem dos produtos comercializados na feira da Quatorze, município de Capanema.

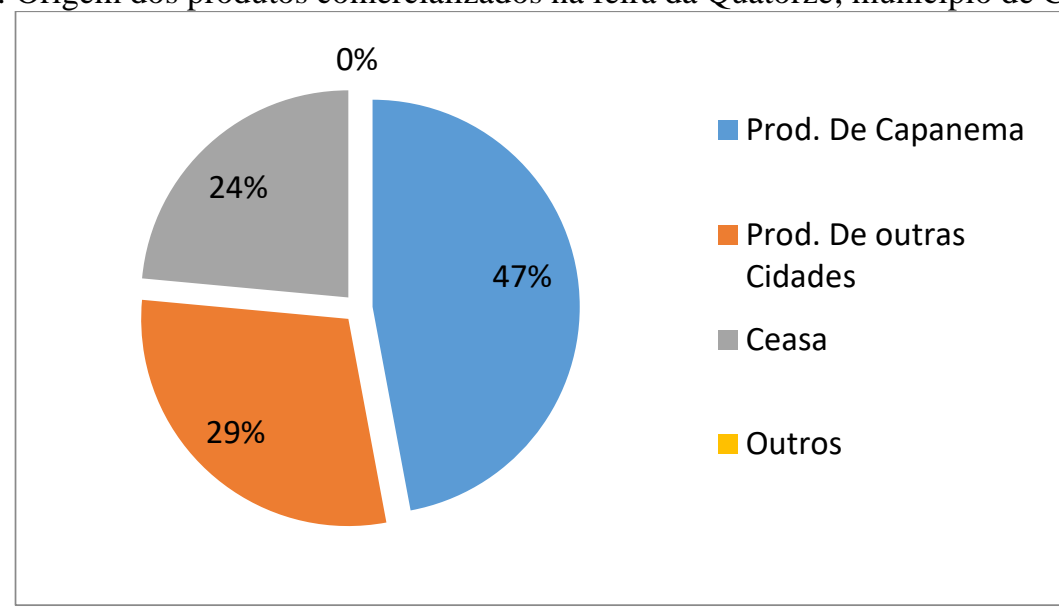

Fonte: Própria (2019).

Com o objetivo de saber as estratégias adotadas para potencializar a comercialização, foi perguntado aos feirantes se participavam de algum tipo de organização. No entanto, apenas $18 \%$ responderam que sim, afirmando terem conhecimento dessas organizações a partir do convite de outros membros mais antigos. Para Coelho e Pinheiro (2009), a organização dos feirantes se faz necessário para obter maiores sucessos em competições com mercados varejistas, buscando para isso apoio, seja ele público ou não. 
Na feira da Quatorze foi observado ausência de qualquer tipo de organização, especifica para os feirantes do local. Quando questionados sobre o interesse em participar de algum tipo de organização $50 \%$ deles responderam que sim, desse percentual a grande maioria (89\%) afirmaram não estar participando de nenhuma organização pela ausência desse tipo de estratégia comercial e $11 \%$ pela burocracia (figura 2 ).

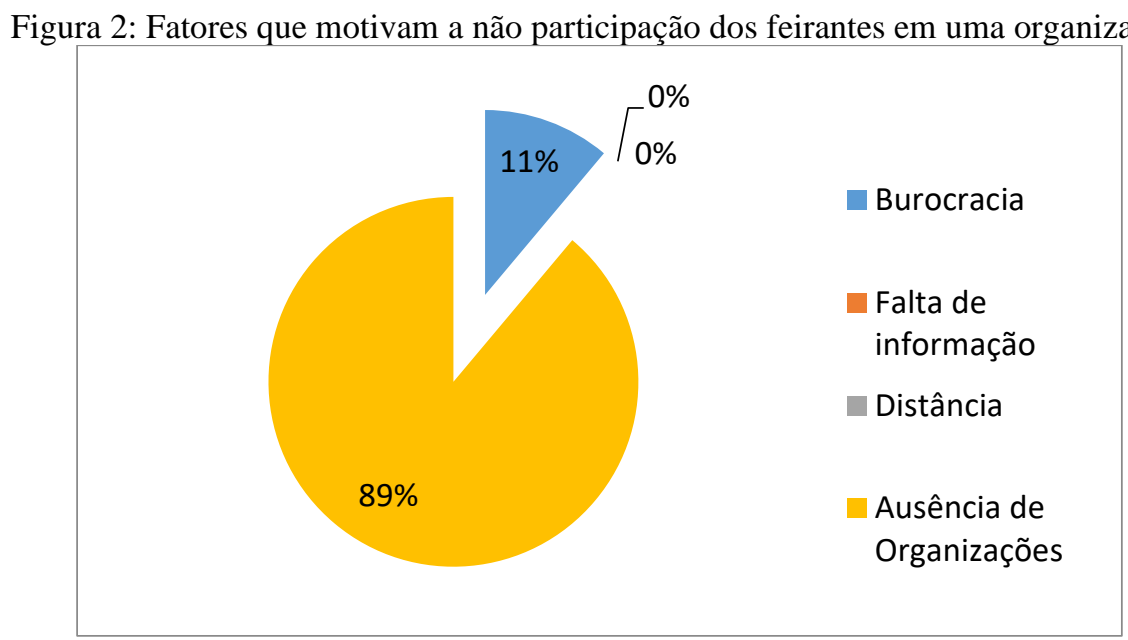

Fonte: Própria (2019).

Constatou-se, ainda que $64 \%$ dos produtos comercializados na feira não são produzidos de forma orgânica. Este resultado deve-se, em parte, a maior demanda por produtos convencionais, que por sua vez correspondeu a $82 \%$ dos produtos comercializados na feira (figura 3). Outro fator motivador desse resultado é a renda dos consumidores que frequentam a feira, uma vez que os demandantes são, em sua maioria, pessoas com menor poder aquisitivo, tendo em vista que os produtos orgânicos são mais valorizados, por maiores dificuldades na produção quando comparados com os convencionais. Morais et al. (2013), estudando o perfil dos consumidores de produtos orgânicos em Goiânia-GO, afirmaram que a escolaridade e renda são fatores que influenciam no consumo de produtos orgânicos, sendo esta uma relação diretamente proporcional.

Figura 3: Tipos de produtos mais demandados na feita da Quatorze, município de Capanema. 


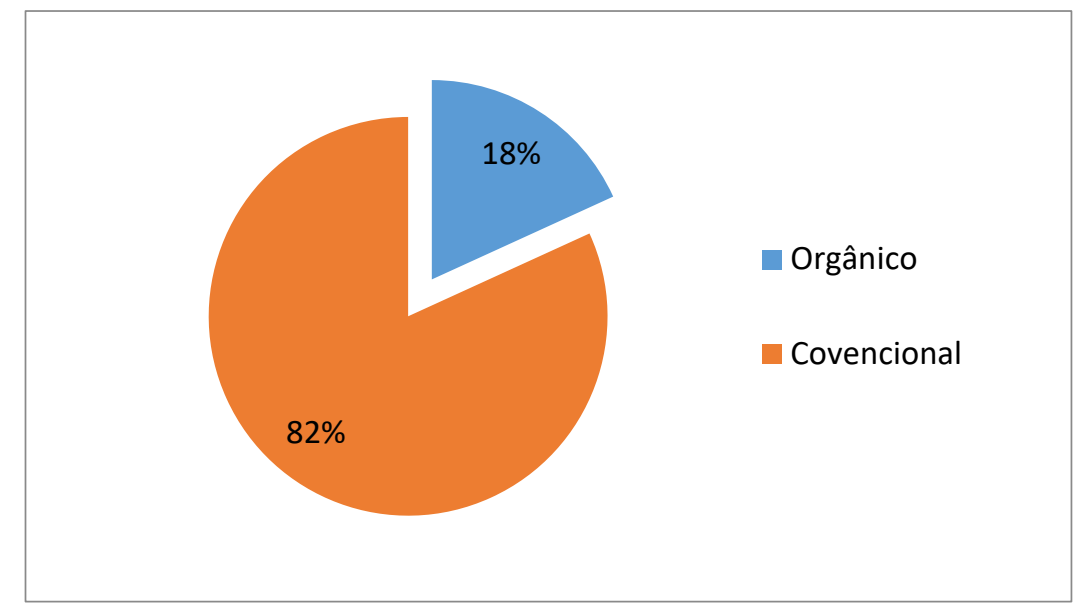

Fonte: Própria (2019)

Foi perguntado aos feirantes participantes da pesquisa se estes investiam em algum tipo de marketing como estratégia de comercialização, 55\% dos entrevistados responderam que sim. Posteriormente, foram questionados sobre quais das principais técnicas que mais utilizavam para conquistar o consumidor: Estes responderam que fazem uso de embalagem personalizada, promoção, cortesia, exposição dos produtos em feiras agrícolas e outros, onde os dados obtidos estão expostos na figura 4. O uso de cortesia é uma prática bastante comum nos espaços da feira em estudo, sendo caracterizado pelo incremento a mais de algum dos produtos disponíveis no estabelecimento, que não faz, obrigatoriamente, parte do acordo comercial entre o feirante e o consumidor. Nesse espaço tais produtos são popularmente chamados de "agrado".

Figura 4: Principais estratégias comerciais adotadas pelos feirantes da Quatorze de Março.

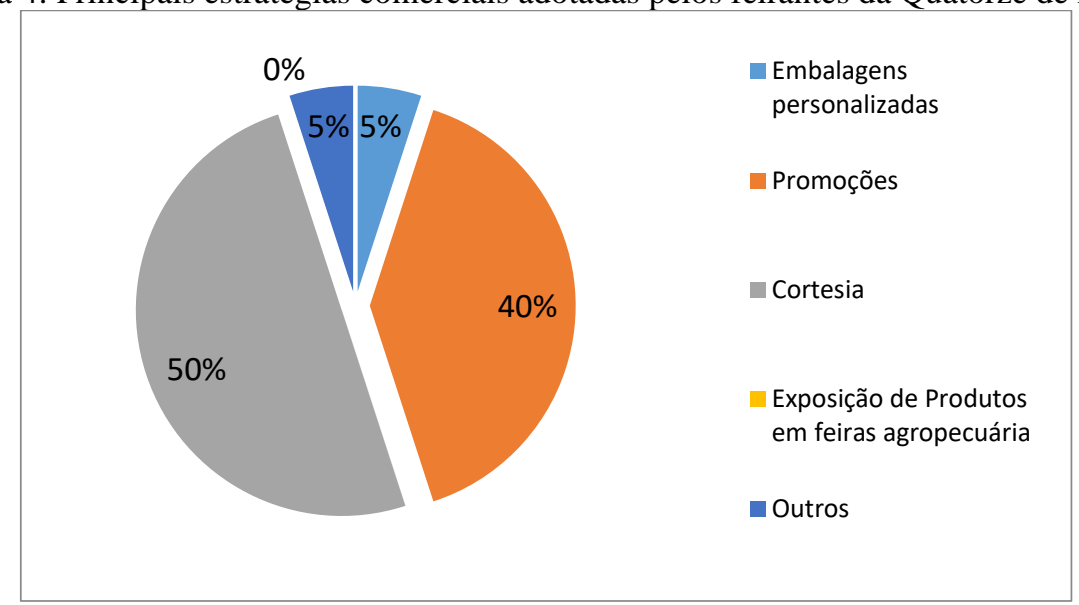

Fonte: Própria (2019). 
Em relação aos principais meios de comunicação utilizados para prover propaganda dos seus produtos, $6 \%$ dos entrevistados respondeu realizar por meio de carro som, $13 \% \mathrm{TV}$, $0 \%$ através de rádio, 25\% pela internet e 56\% "Boca a Boca" (figura 4). Esses resultados tornam-se coerentes quando comparado com as análises realizadas por Souza et al. (2015), sobre as estruturas de comercialização: ações de marketing informal por microempreendedores em uma feira-livre, onde afirmaram que esse tipo de comunicação utilizada em ambiente de feira consiste na forma mais comum, sendo caracterizada pela utilização de músicas conhecidas, paparicos e gírias que despertam o interesse das pessoas que frequentam o local.

Figura 5: Principais meios de divulgação dos produtos comercializados na feira da quatorze, município de Capanema.

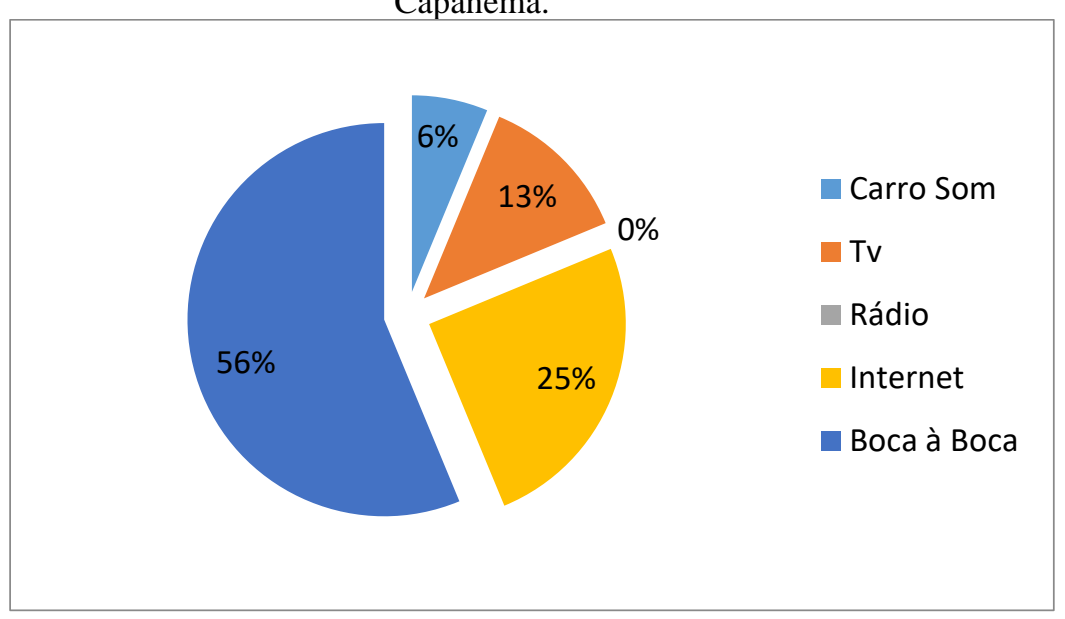

Fonte: Própria (2019)

Um dos maiores entraves enfrentados pelos feirantes da Quatorze é a falta de auxílio e incentivo, por parte do poder público. Isso é percebido quando $91 \%$ dos feirantes admitirem não receber nenhum tipo de assistência, sendo que a assistência técnica prestada aos $9 \%$ que responderam sim é oriunda do setor privado. Além disso, 64\% afirmaram não estar participando (ou nunca ter participado) de nenhum curso ou trocas de experiências e capacitação que promova conhecimentos sobre estratégias de comercialização.

Dos feirantes $27 \%$ afirmaram que a principal dificuldade que enfrentam na comercialização é o preço, pois o mesmo sofre oscilação por fatores de produção. Com $20 \%$ cada, a concorrência e a falta de conhecimento também se constituem dificuldades que os feirantes enfrentam, quando somadas essas dificuldades ficam $40 \%$ o que se torna um valor bem relevante para as dificuldades enfrentadas na comercialização. Transporte e qualidade 
com $13 \%$ apresentam-se em terceiro lugar para as dificuldades e juntas totalizam $26 \%$, tornando esse valor representativo que afeta na venda dos produtos (figura 6).

Para Silveira et al. (2017), a formação do preço de um produto em empresas e realizado após uma análise de mercado e pesquisas realizadas com seus possíveis compradores, afim de que se chegue a um valor aceitável para empresa e para o cliente. $\mathrm{O}$ mesmo autor segue dizendo que para que haja conquista do cliente o feirante deve superar a concorrência, nesses espaços essa conquista está centrada na forma de atendimento, onde é necessário fazer com que o cliente se sinta bem, confortável e superando suas expectativas. Isso permite maior possibilidade de retorno do cliente ao estabelecimento.

Segundo Dantas e Almeida (2013) as dificuldades que fazem parte da feira estão no transporte dos produtos para a mesma, retorno financeiro e pouco incentivo. E no fator da comercialização está na limitação dos produtos, infraestrutura, agrupamento dos mercados e requisições sanitárias. Chiarello; Orlowski; Wackulicz, (2007) registraram um amplo aspectro de dificuldades quanto à venda nas feiras, que por sua vez variam desde a concorrência dos mercados, limite de produtos que podem ser comerciados até as cobranças sanitárias e infraestrutura das feiras.

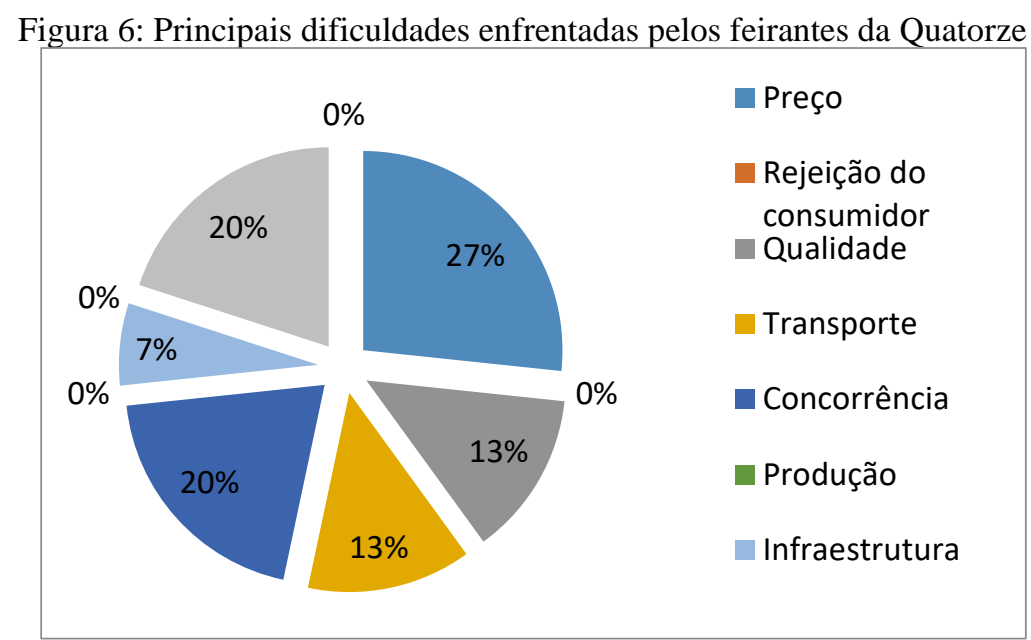

Fonte: Própria (2019).

Quando questionados sobre o auxílio de ógãos públicos para contornar os problemas encontrados, $100 \%$ dos feirantes afirmaram não recebem auxilio. Isso se dá devido a cidade não possuir pessoas capacitadas para essas atividades. De acordo com Corá, Begnini e Rech (2011) se faz necessário políticas públicas para efetivar as atividades de trabalho e cabe ao feirante organizar os produtores e consumidores. 
Em relação aos problemas relacionados a infraestrutura $40 \%$ dos feirantes alegam o fator "espaço insuficiente", sendo este o problema que mais influencia na infraestrutura e dificulta a comercialização, pois os mesmos se limitam na diversidade dos produtos. Em seguida os feirantes alegam que seus estabelecimentos são menos atrativos com $34 \%$ dos resultados. Não ter espaço adequado é a reclamação de muitos feirantes, pois a mercadoria se torna escassa e com pouca variabilidade. E os clientes reclamam pela falta de espaço que atrapalha o fluxo das pessoas e automóveis causando transtorno, e a demanda de produtos insuficientes (VASCONCELOS, 2014).

Figura 7: Problemas na infraestrutura que dificulta a comercialização de produtos na Feira da Quatorze de Março, município de Capanema.

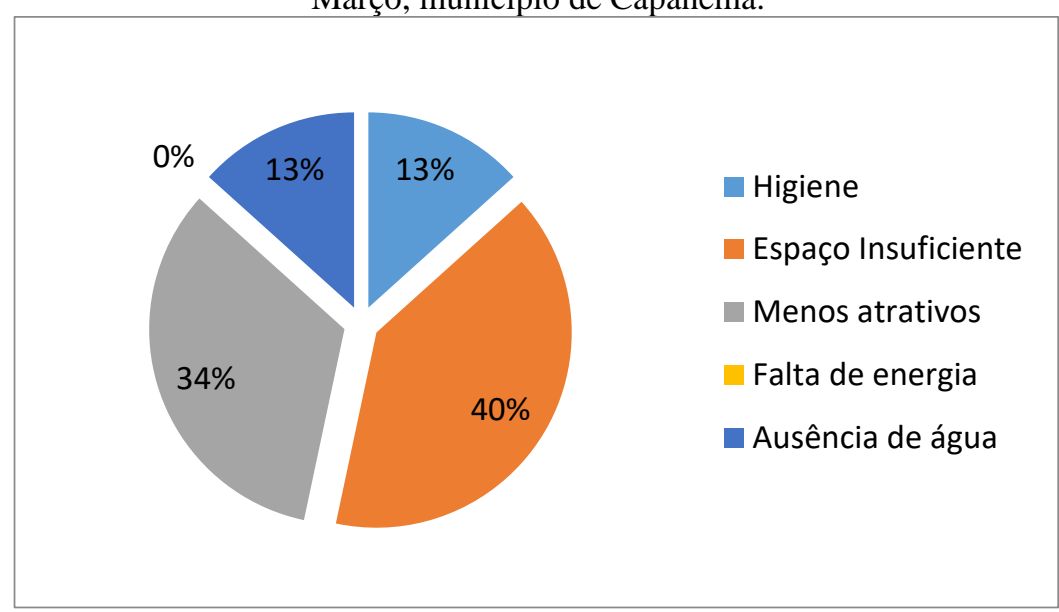

Fonte: Própria (2019)

Conforme os dados obtidos, $64 \%$ dos feirantes encontram-se insatisfeitos com os lucros obtidos, pois alegam ter um retorno econômico abaixo do desejado. Quando interrogados sobre o interesse em melhorar esses resultados econômicos, $100 \%$ dos participantes responderam haver interesse.

O transporte dos produtos até a Feira da Quatorze de Março se dá por conta própria com $91 \%$ dos resultados, pois a maioria dos feirantes já possuem suas conduções até a feira, 9\% deles contam com transporte de terceiros, tornando um gasto de produção a mais e com isso tendo que ajustar o valor do produto ou diminuir sua margem de lucro.

Figura 8: Transporte de produtos dos feirantes da Quatorze de Março, Município de Capanema. 


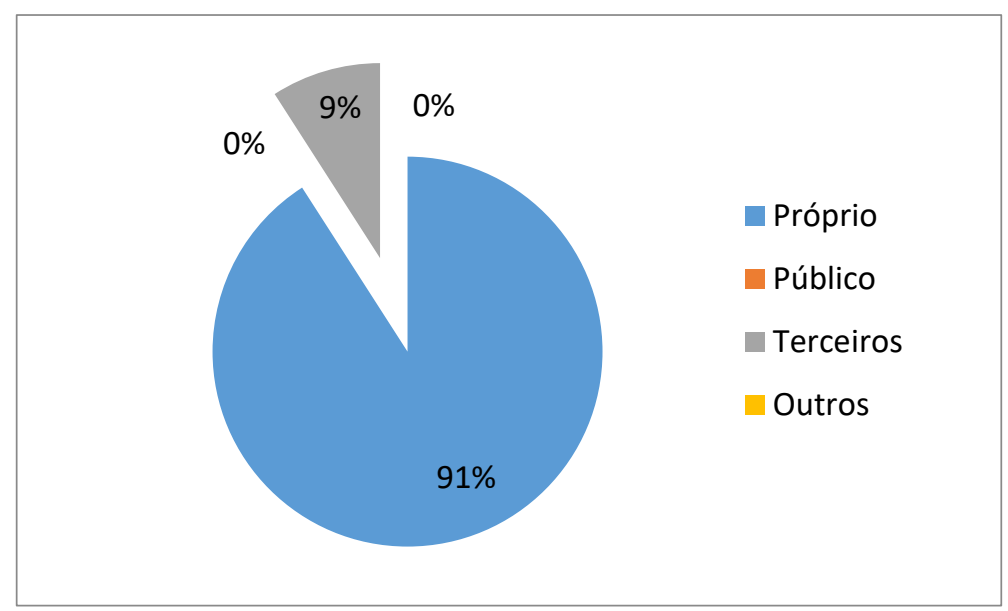

Fonte: Própria (2019)

\section{Conclusões}

Como principal estratégia de comercialização os feirantes, em sua maioria, apostam na divulgação dos seus produtos através do método denominado "Boca a Boca", que consiste no método mais acessível à realidade dos ofertantes.

O fator mais limitante no processo de comercialização nos produtos dos feirantes atuantes na feira da Quatorze é o preço. Espaços insuficiente é o principal problema relacionado a infraestrutura, relatado por eles. Além disso, a ausência de organizações, grupos ou movimentos em favor dessa classe torna-os menos eficientes em suas atividades e com menor poder em buscar soluções para os fatores que mais limitam o sucesso de suas atividades.

É bem visível a falta de interesse pelos feirantes da quatorze de março, por parte do poder público. A precarização dos estabelecimentos e falta de conhecimentos quanto ao processo de comercialização prova tal fato, por tal razão os feirantes estão desenvolvendo suas atividades de forma independente e elaborando suas próprias estratégias de comercialização, fundamentadas em conhecimentos empíricos e com isso tentando contornar suas principais dificuldades.

\section{Referências}

ASSUMPÇÃO, W. Et al. Estratégias do comércio popular de feiras livres e mercados municipais como benchmark para o varejo supermercadista. In: SIMPÓSIO DE REDES DE SUPRIMENTOS E LOGISTICA, 1., 2013, Grande Dourados. Anais. Revista construção e tecnologia. 2014. p. 98-109. 
CHIARELLO, Maralucia; ORLOWSKI, Rosemari Fátima; WACKULICZ, Gilmar Jorge. Feiras livres: uma alternativa de geração de renda aos agricultores familiares de Chapecó (SC). 2007. Trabalho acadêmico, CHAPECÓ - SC, 2007. Disponível em: http://www.apec.unesc.net/II\%20EEC/sessoes_tematicas/Regional/Artigo15.pdf. Acesso em: 12 fev. 2019.

COÊLHO, JACKSON DANTAS ; PINHEIRO2, JOSÉ CÉSAR VIEIRA. GRAU DE ORGANIZAÇÃO ENTRE OS FEIRANTES E PROBLEMAS POR ELES ENFRENTADOS NAS FEIRAS LIVRES DE CASCAVEL E DE OCARA, NO CEARÁ. In: SOCIEDADE BRASILEIRA DE ECONOMIA, ADMINISTRAÇÃO E SOCIOLOGIA RURAL, 2009, Porto Alegre. Anais [...]. Porto Alegre: Sociedade Brasileira de Economia, Administração e Sociologia Rural, 2009.

CORÁ, Marisa Biali; BEGNINI, Leomar; RECH, Rogério. Análise sócio-econômica da associação de feirantes do municipio de realeza-pr. 2011. Trabalho acadêmico (Graduação em administração), Pato Branco, 2011.

DANTAS, Severino Ranielson Cunha; ALMEIDA, Milene Félix de. FORTALECIMENTO DAS ESTRATÉGIAS DE COMERCIALIZAÇÃO NA FEIRA AGROECOLÓGICA DE SOLÂNEA - PB. 2013. Trabalho acadêmico, SOLÂNEA - PB, 2013. Disponível em: http://www.prac.ufpb.br/enex/trabalhos/8CCHSADCSAPROBEX2012215.pdf. Acesso em: 12 fev. 2019.

DE JESUS TELLO, Jean Paulo et al. ASPECTOS SOCIOECONÔMICOS E DE COMERCIALIZAÇÃO DOS VENDEDORES DE HORTALIÇAS DO LADO BRASILEIRO DA TRÍPLICE FRONTEIRA (BRASIL-PERU-COLÔMBIA). Cultura Agronômica: Revista de Ciências Agronômicas, v. 24, n. 3, p. 275-288, 2015.

DIAS, Eduardo Carvalho; SANTOS, Wellington Barros; ALMEIDA, Grace Q. Mesquita. Estratégias Econômicas em Diálogo com a Agroecologia. Comercialização de Produtos Agroecologicos na Feira Livre de Dianópolis - TO, Brasilia - DF, 2018. Disponível em: cadernos.aba-agroecologia.org.br/index.php/cadernos/article/download/164/1598/. Acesso em: 12 fev. 2019.

GODOY, Wilson Itamar; DOS ANJOS, Flávio Sacco. A importância das feiras livres ecológicas: um espaço de trocas e saberes da economia local. II Congresso Brasileiro de Agroecologia, [S. 1.], ano 2007, v. 2, n. 1, 2007.

GODOY, T. A esfera da troca na economia solidária: comércio e consumo solidário na cidade. Artigo apresentado no XII Simpósio Nacional de Geografia Urbana. Belo Horizonte, 2011.

MICHELLON, Ednaldo et al. Feira do produtor e os Entraves à Sua Organização e à Comercialização: o Caso de Paiçandu. In: XLV Congresso da Sociedade Brasileira de Economia, Administração e Sociologia Rural (Sober). UEL-Londrina. 2007. 
MORAIS, Fernando Ferrari de et al. Perfil dos consumidores de produtos orgânicos da feira agroecológica do mercado municipal de Goiânia-GO. Revista Verde de Agroecologia e Desenvolvimento Sustentável, [S. l.], 2012.

QUEIROZ, Maria Clara; PIERRI, Mauricio; VALENTE, Ana Lucia E. F. A FEIRA LIVRE COMO CANAL DE COMERCIALIZAÇÃO DE PRODUTOS DA AGRICULTURA FAMILIAR. [20-?]. Trabalho acadêmico, Brasília - DF, [20-?]. Disponível em: http://www.sober.org.br/palestra/15/234.pdf. Acesso em: 12 fev. 2019.

SILVEIRA, Vítor Cardoso et al. AVALIAÇÃO DA IMPORTÂNCIA DAS FEIRAS LIVRES E A FORMA DE COMERCIALIZAÇÃO ADOTADA PELOS FEIRANTES NA CIDADE DE NOVA ANDRADINA-MS. Encontro Internacional de Gestão, Desenvolvimento e Inovação (EIGEDIN), v. 1, n. 1, 2017.

SOUZA, Gustavo Henrique Silva de et al. ESTRUTURAS DE COMERCIALIZAÇÃO: AÇÕES DE MARKETING INFORMAL POR MICROEMPREENDEDORES EM UMA FEIRA-LIVRE. 2015. Trabalho acadêmico, [S. l.], 2015.

VASCONCELOS, Jéssica. Feira da Banana já não possui espaço para armazenar produtos. Manaus - $A M, 2014.2$ Disponível em: https://www.acritica.com/channels/manaus/news/feira-da-banana-ja-nao-possui-espaco-paraarmazenar-produtos. Acesso em: 12 fev. 2019. 